\title{
9. THE NEW FLARE SPECTROGRAPH AT ONDREJOV
}

\section{ZD. SVESTKA}

We present here several examples of flare spectra obtained by the new flare spectrograph built at Ondrejov, Czechoslovakia. The spectrograph, finished in May of this year, works in five spectral regions, $\mathrm{H} \alpha, \mathrm{D}_{1}{ }_{2}{ }_{3}, \mathrm{H} \beta, \mathrm{H} \gamma$, and $\mathrm{H}$ and $\mathrm{K}$, taking simultaneously broad surroundings of these lines on five plates, with a dispersion of $I \AA / \mathrm{mm}$. The focal length of our objective mirror is $14.5 \mathrm{~m}$, the size of the grating is $9 \times 10 \mathrm{~cm}$. We get our spectra in the second order of the grating; the first order is used for guiding in the $H \alpha$ line. The plates are calibrated by means of a scale, which is placed on the slit and illuminated by the centre of the solar disk.

We show here (not reproduced) one set of plates containing successive spectra-at $\mathrm{I}^{\mathrm{m}}$ intervals - of the great flare of $195^{8}$ July 20 . These spectra cover the whole development of the flare, almost from its first appearance on the disk, so that we may follow here the pre-maximum, maximum, as well as the post-maximum phase. Further we present several other flare spectra, which are of some interest as to the asymmetry of the emission lines, their distortions, or a great number of reversals in the metallic lines.

\section{EJECTIONS DE MATIERE ABSORBANTE AU COURS D'ÉRUPTIONS CHROMOSPHÉRIQUES \\ Mme M. D'AZAMBUJA}

Les enregistrements cinématographiques de la chromosphère solaire, à l'aide de l'héliographe automatique de Meudon, ont permis de constater par trois fois, au début d'éruptions chromosphériques importantes, des éjections de matière absorbante se déplaçant sur des distances pouvant aller jusqu'à un rayon solaire, durant un intervalle de temps de l'ordre d'un quart d'heure. Cette absorption a été simultanément relevée sur des spectrohéliogrammes $K_{1}$, à $I \cdot 2$ ångström du milieu de la raie. On peut se demander si elle ne correspondrait pas aux émissions corpusculaires prévues par la théorie de Chapman et que les contours de raies au microphotomètre n'ont pu jusqu'ici mettre en évidence avec certitude.

\section{BALMER SERIES LINES IN FLARE SPECTRA}

\section{Z. SUEMOTO AND E. HIEI}

Many spectra of flares have been taken at the Tokyo Astronomical Observatory with a newly-built wide-range spectrograph. On this instrument the spectrum covering the whole Balmer series lines and continuum can be recorded with a dispersion of about $3 \cdot 2 \AA / \mathrm{mm}$ on commercial $35 \mathrm{~mm}$ film of about $\mathrm{I} 50 \mathrm{~cm}$ in length by a single exposure. So far we have measured Balmer series lines for only four flare spectra of flares of importance 2 . But the results obtained appear to us remarkable.

Profiles of flare spectra were compared with the profiles of normal spectra in the neighbourhood of flares and suitable corrections were made to obtain a 'reduced profile' for the flare spectrum.

When the total half-widths of the 'reduced profiles' of the Balmer series lines are plotted against their principal quantum number $n$, the half-widths show a minimum at about $n=8$, and the whole plots are best fitted by a theoretical curve with the following values: $T_{e}=\mathrm{I} 5,000^{\circ}, n_{2} H^{*}=8 \times \mathrm{IO}^{14} \mathrm{~cm}^{-2}$ and $n_{e}=\mathrm{IO}^{13} \mathrm{~cm}^{-3} . H^{*}$ is the effective thickness of the flare layer.

If we take $T_{\mathrm{exc}}=5600^{\circ}$ for the relative population between $n=2$ and $n=8$, which is estimated from the saturated central intensities of the earlier members, we find $n_{\mathbf{8}} H^{*}=$ 